\title{
PASSEIOS HAMLETIANOS NA CONTEMPORANEIDADE: NARRATIVA METAFICCIONAL
}

\author{
Cícera Antoniele Cajazeiras da Silva*
}

\begin{abstract}
Resumo:A metaficção - fenômeno literário no qual a narrativa chama atenção para si mesma, ressaltando seu status de artifício - reflete as palavras de Julio Cortázar no ensaio Do sentimento de não estar de todo ao designar como "passeiozinhos hamletianos" (paseítos hamletianos) as reflexões que suas narrativas propõem acerca da linguagem literária e as experimentações textuais por meio das quais o autor põe em xeque o discurso literário, expondo suas vulnerabilidades através da inserção do discurso crítico em meio ao texto. O presente trabalho pretende - a partir do conto As babas do diabo, publicado na coletânea As armas secretas, do referido autor argentino - propor uma leitura analítica da dinâmica de construção metaficcional na narrativa. Levando em consideração as colocações teóricas de Linda Hutcheon, Patricia Waugh, Robert Stam, Mark Currie, Gustavo Bernardo Krause, entre outros, busca-se ainda evidenciar o reconhecimento e a compreensão dos procedimentos metaficcionais como fundamentais ao processo de atribuição de sentido às referidas manifestações textuais.
\end{abstract}

Palavras-chave: Narrativa. Metaficção. Contemporaneidade.

\begin{abstract}
The metafiction - literary phenomenon in which the narrative draws attention to itself, emphasizing its status as an artifice - reflects the words of Julio Cortázar in the essay Do sentimento de não estar de todo when designating as "pequenos passeios hamletianos" the reflections that his narratives propose about the literary language and the textual experiments through which the author puts the literary discourse in check, exposing its vulnerabilities through the insertion of the critical discourse in the middle of the text. The present work intends to propose an analytical reading of the metafictional construction dynamics in the narrative. Taking into account the theoretical positions of Linda Hutcheon, Patricia Waugh, Robert Stam, Mark Currie, Gustavo Bernardo Krause, among others, it is also tried to highlight the recognition and understanding of the metafictional procedures as fundamental to the process of attribution of meaning to the mentioned manifestations texts.
\end{abstract}

Keywords: Narrative. Metafiction. Contemporaneity.

\section{Iniciando o passeio: algumas considerações teóricas sobre metaficção}

Em meados do século XX, o fenômeno da autoconsciência que - conforme foi discutido anteriormente - já se fazia presente em alguns textos literários que remetem à tradição literária, passou por um processo de radicalização que levou a uma significativa transformação da narrativa literária.

Escritores como John Barth, Italo Calvino, John Fowles, Kurt Vonnegut, Jorge Luis Borges, Samuel Beckett, José Saramago, Mia Couto, Donald Barthelme, Muriel Spark, Thomas Pynchon, Julio Cortázar, Ian McEwan, Graham Greene, Angela Carter apresentam o interesse comum pela atividade de minar convenções literárias, tradicionalmente estabelecidas como critério qualitativo da obra literária (muito embora grande parte do cânone literário seja composta por textos plenos de procedimentos autorreflexivos). Essa conduta revela textos em que emergem traços de narrativas completamente envolvidas com a discussão e/ou tematização dos aspectos relacionados à literatura - composição textual, potencial linguístico da escrita, peso da tradição, elementos narrativos e suas funcionalidades, paradigmas narrativos, recepção, crítica, leitura e significação -, estabelecendo uma permanente relação de diálogo crítico com o passado literário.

\footnotetext{
* Doutora em Letras pela Universidade Federal da Paraíba - UFPB. Professora da Universidade Federal Rural do Semi-Árido - UFERSA ciceraantonielle@gmail.com
} 
A função metalinguística foi definida por Jakobson como a função da linguagem que "focaliza o código" (2003, p. 126) ou veicula informações sobre ele. A metaficção, considerada por Bernardo a "irmã mais nova da metalinguagem" (2010, p.9), seria a manifestação narrativa da metalinguagem, isto é, quando a ficção se volta para seu próprio código - a narrativa - e expõe seus mecanismos de construção para o público leitor, no sentido de identificar os elementos de composição artística - e o próprio texto - como artifícios e de questionar a noção de realidade que tradicionalmente se constrói na narrativa literária.

Mencionado pela primeira vez na coletânea de ensaios Fiction and the figures of life (1970), de William H. Gass, o termo metaficção desencadeou uma série de tentativas de definição. Segundo Gass (apud CURRIE, 1995, p.1), trata-se da ficção marcada pela autoconsciência, pelo autoconhecimento e pelo distanciamento autoirônico.

Ainda na década de 1970, Robert Scholes, no ensaio intitulado Metafiction, procura realizar o desdobramento do termo proposto por Gass, argumentando que a metaficção seria um discurso limítrofe, resultante da inseparabilidade de ficção e crítica perceptível nesses textos. Scholes afirma que a metaficção "tenta, entre outras coisas, atacar ou transcender as leis da ficção - uma tarefa que só pode ser cumprida de dentro da forma ficcional" (1995, p.29), chamando atenção para a presença do discurso crítico no interior da narrativa metaficcional.

Nos anos 80, intensificam-se os esforços em função da compreensão das manifestações metaficcionais na literatura com a publicação de dois títulos fundamentais ao estudo mais aprofundado do assunto. Linda Hutcheon, em Narcissistic narrative: the metaficcional paradox, publicado em 1980, define preliminarmente metaficção como "ficção sobre ficção - isto é ficção que inclui em si mesma um comentário sobre sua própria identidade narrativa e/ou linguística" (1991, p.1) e se dedica a uma ampla discussão sobre os modos e as formas pelos quais o fenômeno se apresenta. Assim como Scholes, Hutcheon aponta para a inserção da crítica em meio à narrativa; aspecto que, para a autora, sinaliza o motivo pelo qual a aproximação teóricocrítica efetiva ocorreu tardiamente, e suscita a necessidade de diversas noções teóricas para a realização de um estudo mais completo acerca da metaficção:

Não foi feita nenhuma tentativa de propor uma teoria abrangente da metaficção [até então]. Em primeiro lugar, qualquer teoria seria reducionista, mais reducionista que qualquer outra teoria do romance em geral. Isto ocorre porque o ponto da metaficção é que ela constitui seu primeiro comentário crítico e, ao fazê-lo, estabelece o quadro teórico no qual deve ser considerada. [...] Se a narrativa autoconsciente por definição inclui em si mesma sua primeira leitura contextual, uma única teoria não será capaz de lidar com ela sem distorção considerável (1991, p.6).

Patricia Waugh, em Metafiction: the theory and practice of self-conscious fiction, publicado pela primeira vez em 1984, reafirma a estreita ligação entre fícção e crítica, mas também chama atenção para o fato de que, ao chamar atenção para a natureza artificial de seus procedimentos e elementos constituintes, o texto metaficcional também questiona os limites de realidade e ficção. Waugh aprofunda a discussão sobre a natureza desse fenômeno estético, percebendo que o texto metaficcional pode por em cheque, inclusive, a aparente realidade do mundo cotidiano:

Metaficção é o termo dado à escrita ficcional que, de forma autoconsciente e sistemática, chama atenção para seu status de artefato 
a fim de propor questionamentos sobre a relação entre ficção e realidade. Promovendo uma crítica de seus próprios métodos de construção, esses textos não examinam apenas as estruturas fundamentais da narrativa ficcional, eles também exploram a possível ficcionalidade do mundo exterior ao texto literário (1984, p.2).

Contemplando a feição filosófica do discurso metaficcional, Waugh traz à tona a matriz dos dilemas com os quais a narrativa metaficcional se encontra envolvida, isto é, a questão das potencialidades da linguagem (inclusive a artística). Retomando o princípio da incerteza de Werner Heinsenberg (segundo o qual seria impossível descrever um mundo objetivo porque o observador teria sempre uma noção distorcida do mesmo, mas que reconhece a possiblidade de se descrever a relação de um observador com esse mundo), Waugh ressalta a forma radical e, ao mesmo tempo, plenamente lúcida, como a metaficção concebe a questão da representação:

O autor metaficcional é altamente consciente de um dilema básico: se ele ou ela se propõe a 'representar' o mundo, ele ou ela percebe rapidamente que o mundo como tal não pode ser 'representado'. Na ficção literária é possível representar apenas os discursos desse mundo (1984, p.3).

Essa consciência das limitações da linguagem encontra expressão na própria narrativa, que através da retomada de estratégias convencionais de representação, chama atenção para a vulnerabilidade dos mundos construídos por meio das diretrizes estéticas consagradas pelo senso comum. Esse caminho leva, portanto, à desmistificação das técnicas de construção narrativa mais conhecidas pelo público leitor:

Romances metaficcionais tendem a ser construídos com base em uma oposição fundamental e sustentada: a construção de uma ilusão ficcional (como no realismo tradicional) e o desnudamento dessa ilusão. Em outras palavras, o menor denominador comum da metaficção é, simultaneamente, criar uma ficção e fazer um comentário sobre a criação dessa ficção. Os dois processos são mantidos em uma tensão formal que rompe com as distinções entre 'criação' e 'crítica' e as associa aos conceitos de 'interpretação' e 'desconstrução' (WAUGH, 1984, p.6).

Levando em consideração a irreverência estética delineada pelo modus operandi metaficcional, a referida modalidade narrativa acaba por minar também a relação leitor/texto. Se a metaficcionalidade do texto narrativo se expressa, sobretudo, por meio do ataque sistemático às convenções e aos lugares-comuns relacionados à questão da escrita e da leitura, o leitor obviamente perde alguns dos referenciais que atribuíam certa estabilidade à sua interação com o texto literário. Diante de um texto que põe em xeque suas próprias estratégias de produção, o leitor não tem outra escolha a não ser o engajamento efetivo com a significação.

Para Waugh (1984, p.18), o leitor desempenha um papel tão fundamental quanto o das personagens, visto que está sempre sendo alertado - pela própria história e pelos procedimentos narrativos - que os eventos diegéticos e seus elementos constituintes não passam de artifícios literários.

Linda Hutcheon, por sua vez, demonstrando maior interesse nas implicações da metaficção para as condutas assumidas pelo leitor, acredita que a relação que ele trava com o autor e com o texto se configura como um paradoxo; a narrativa procede de 
forma a forçá-lo a reconhecer o caráter artificial do que está lendo ao mesmo tempo em que promove seu envolvimento intelectual e afetivo com a história, exigindo, dessa forma, que ele assuma responsabilidades de coautor (1991, p.5), participando ativamente da criação tanto dos mundos ficcionais, como do significado (1991, p.30). A metaficção, assim, desestabiliza os elementos textuais de forma tão ostensiva e ampla, que até mesmo entidades bem consolidadas, como leitor, autor e narrador passam a ser reconsideradas. Dessa forma, torna-se inquestionável a natureza autoconsciente do discurso metaficcional, reafirmada por estudiosos que, posteriormente a Hutcheon e Waugh, discutiram criticamente o fenômeno.

David Lodge, em conformidade com as concepções citadas anteriormente, define metaficção como "ficção que versa sobre si mesma, romances e contos que chamam atenção para o status ficcional e o método usado em sua escritura" (2010, p.213). Gustavo Bernardo, reforçando a configuração autorreflexiva que a narrativa assume, afirma que a metaficcionalidade seria "um fenômeno estético autorreferente através do qual a ficção duplica-se por dentro, falando de si mesma ou contendo a si mesma" (2010, p.9). Já Mark Currie, considera que autoconsciência não é parâmetro suficiente para definir os contornos da metaficção, a propósito das múltiplas configurações que se apresentam na referida modalidade narrativa. Currie focaliza, portanto, o hibridismo do discurso metaficcional, marcado pela presença da crítica em meio à tessitura narrativa e à história (1995, p.2).

A ocorrência simultânea de discursos aparentemente díspares, como ficção e crítica, a dissolução de convenções ligadas aos aspectos narrativos até então perfeitamente cristalizadas - narrador, leitor, personagem, história e realismo - e a presença da autorreflexividade colocam em evidência que a metaficção se estabelece como a expressão estética de uma insegurança ontológica que diz respeito ao ser humano, à arte e à linguagem e é comum a diversas épocas, mas abordada de forma ainda mais obsessiva na contemporaneidade.

Embora a noção de ruptura seja evidente no texto metaficcional, cabe compreender que a frustração de expectativas e o rompimento de convenções promovidos pela metaficção não revelam unicamente seu caráter subversivo; esses recursos procuram disseminar a mudança de conduta do público consumidor de arte, invocando sua participação, atribuindo-lhe responsabilidade tão relevante quanto à do próprio autor.

A metaficção nos relembra (ou nos ensina) que o discurso literário depende do leitor para que se torne completo. Com isso, fica evidente também que a relação do texto metaficcional com o realismo não é de mera rebeldia:

A metaficção não abandona o "mundo real" em nome dos prazeres narcisistas da imaginação. $\mathrm{O}$ que ela faz é reexaminar as convenções do realismo, a fim de descobrir - através da sua própria autorreflexão - uma forma ficcional que seja culturalmente relevante $\mathrm{e}$ compreensível para os leitores contemporâneos. Mostrando-nos como a ficção literária cria seus mundos imaginários, a metaficção nos auxilia a compreender como a realidade cotidiana é igualmente construída, igualmente "escrita" (WAUGH, 1984, p.18).

Essa incerteza ontológica - isto é, a coexistência de padrões do realismo e de estratégias de desmitificação dos mesmos - abrange as concepções de realidade e ficção e mina até mesmo as certezas do leitor em relação ao seu cotidiano, levando o público a reconhecer que, assim como a ficção literária é um constructo, sua realidade também pode ser considerada resultado de uma construção que visa ordenar sua experiência de 
modo a atribuir-lhe sentido. A atitude de desconstrução, portanto, revela-se como a principal aliada dos procedimentos da metaficção que se envolvem na reavaliação das formas ficcionais vigentes e na busca por respostas ao impasse do texto:

A desconstrução metaficcional não só forneceu aos autores e leitores uma melhor compreensão das estruturas narrativas fundamentais, mas também ofereceu modelos de compreensão da experiência do mundo contemporâneo como uma construção, um artifício, uma rede semiótica interdependente. A paranoia que permeia a escrita de metaficção nos anos 60 e 70 está, portanto, cedendo à celebração, à descoberta de novas formas de fantástico, de extravagâncias fabulares e de realismo mágico (WAUGH, 1984, p.9).

No sentido de reconsiderar seu próprio código, de reavaliar as estruturas ficcionais, a narrativa metaficcional volta-se para dentro, ao mesmo tempo em que se coloca diante do espelho. Exibindo o que diz respeito à sua essência e hiperbolizando esses aspectos por meio de procedimentos reflexivos, a metaficção incorpora sua crise de identidade ao material narrativo.

\section{Dos passeios hamletianos de Cortázar em Las babas del diablo}

As babas do diabo emerge do universo ficcional cortazariano como conto em que as expectativas em relação à fábula são frustradas em nome do investimento desmistificador dos mais distintos aspectos inerentes à composição literária narrativa e, consequentemente, do questionamento das estratégias de recriação da realidade na literatura.

Publicado pela primeira vez na coletânea As armas secretas (Las armas secretas), em 1959, o conto As babas do diabo (Las babas del diablo) é considerado a primeira narrativa abertamente metaficcional do autor argentino (COUTINHO, 1985, p.37). Ocupando uma reunião de contos em que esse aspecto se deixa entrever ao longo de uma tessitura aberta e profunda, como em $O$ perseguidor (El perseguidor), a narrativa em questão radicaliza os procedimentos que se esboçavam ao longo de uma produção literária que se mostra permanentemente envolvida com o questionamento e a subversão de fórmulas e formas fixas da práxis literária.

Desde suas primeiras publicações, Cortázar anuncia seu interesse pelo desnudamento e/ou pela exposição das fraturas que (naturalmente) constituem a construção ficcional. Em Casa tomada, seu conto de estreia, o desinteresse da narrativa em construir explicações ou mesmo apontar indícios que justificassem a natureza dos eventos diegéticos expõe um dos mais frequentes instrumentos de quebra dos padrões composicionais na narrativa cortazariana: o fantástico.

Em As babas do diabo, esse aspecto também se faz presente engajando-se não apenas na construção de uma narrativa de caráter sobrenatural e/ou insólito, como também minando as noções de realidade que - tradicionalmente - integram o horizonte de expectativas em relação à ficção literária. No entanto, a irrupção do fantástico é apenas um dos recursos que promovem a atmosfera de estranhamento, ruptura e rebelião frente às práticas narrativas consagradas.

No conto, o protagonista - que inicialmente se dedica a um trabalho de tradução - realiza um registro fotográfico de uma cena aparentemente corriqueira que se revela permeada de possibilidades interpretativas que o mergulham em um imbricado jogo de busca pelo (s) sentido (s) da imagem capturada. A essa fábula, mais adaptada às expectativas do senso comum em relação à ficção - associam-se artifícios que fazem 
emergir estratos nos quais se fazem perceptíveis as pretensões desmistificadoras da narrativa em relação a seus próprios procedimentos e efeitos.

A experiência do fotógrafo e tradutor Roberto Michel frente ao poder imagético e narrativo de uma instantânea é sugestiva da discussão autorreferencial que se materializa ao longo do desenvolvimento do conto. Sua busca por significado traduz a incursão do leitor no universo de questionamento dos meios pelos quais uma história se mostra a seus olhos. Além disso, a presença da fotografia - tanto a prática, como o produto - propõe uma analogia entre as vastas possibilidades narrativas de um registro fotográfico (constituído de silêncio e amplitude) e o potencial semântico do gênero conto (permeado de lacunas e porosidade), como sugere o próprio Cortázar em Alguns aspectos do conto.

Considerado também uma das narrativas mais complexas do autor argentino (ARRIGUCCI, 1995, p.227), ao lado de O jogo da amarelinha (Rayuella), o conto desenvolve níveis diegéticos distintos - a história de uma fotografia que supostamente mostra mais do que foi registrado, entrecortada pela dramatização da composição da história que se conta (ou se busca contar) - além de distintos níveis interpretativos cuja profundidade se revela a partir da leitura atenta às "particularidades aparentemente secundárias" (p.227) da tessitura narrativa. Esses aspectos se materializam em divagações do (s) narrador (es); passagens (não) narrativas em que se impõe a ruptura do fluxo da história como meio de refletir sobre sua dinâmica de construção.

Ainda para Arrigucci, esses aspectos estabelecem também a analogia entre a figura do fotógrafo e a do leitor, uma vez que as camadas profundas do texto seriam alcançadas apenas por meio da adoção dessa postura inquiridora, atenta a detalhes, isto é, através do desenvolvimento de um olhar que busca o significativo em meio ao (aparentemente) trivial:

Desde o primeiro contacto, [a narrativa] parece exigir do leitor a mesma visão detida e minuciosa desse fotógrafo que busca a revelação do verdadeiro sentido de uma cena, à primeira vista banal e sem sentido. E, desde o princípio, convida-o a enveredar-se por meandros que parecem distanciá-lo do foco de interesse da história, encerrandoo num labirinto de divagações, do mesmo modo que o mundo múltiplo e caótico desafia e desnorteia a câmara fotográfica, à caça do retalho significativo, do fragmento que, com força de forma significante, abra para uma realidade mais ampla $(1995$, p.227).

Desse modo, a fotografia se mostra como representação do próprio conto e do texto literário de uma forma geral, bem como o trabalho do fotógrafo sugere o processo de leitura e significação empreendido pelo leitor, que consiste em um trabalho tão intenso quanto o da própria criação artística. Essa representação instaura no texto a complexa teia de aspectos autorreflexivos que, além de evidenciar o ponto de vista cortazariano sobre a produção textual, transfiguram as experiências de composição e de leitura em um verdadeiro itinerário desnorteador em meio à realidade insondável e impassível de captura.

A natureza insondável dos fatos vividos pelo narrador e personagem atribui complexidade à tarefa de contar, provocando a hesitação do narrador em relação a como e por que narrar. O embate e a diluição de limites entre o "real" e o "irreal" remetem à questão da representação/recriação da realidade pelo texto literário, ocasionando a indefinição em relação ao foco narrativo como uma das problemáticas que permanece sem solução - ou, pelo menos, sem solução "fácil" - convertendo-se em um foco narrativo duplo, que oscila entre primeira e terceira pessoa. 
O narrador em primeira pessoa - o fotógrafo e tradutor Roberto Michel, sujeito que vivencia os acontecimentos - mostra-se perdido em meio às suas incertezas em relação ao que busca contar. Tal qual o criador literário, protagoniza um momento de crise ao perceber que nenhum esforço técnico ou mesmo estético será capaz de contemplar - tampouco lançar luz sobre - todas as facetas da experiência a ser representada.

Diante das limitações que uma única instância narrativa apresenta diante da natureza dos eventos, surge a onisciência narrativa. $\mathrm{O}$ que parecia ser uma solução regularizadora da narrativa, isto é, uma estratégia em nome de uma provável guinada para os padrões composicionais mais alinhados ao senso comum - torna-se mais um recurso subversivo, uma vez que ocorre a alternância entre o narrador em primeira pessoa e o narrador em terceira pessoa e não a substituição de um pelo outro. Desse modo, a narrativa segue orientada por um narrador duplicado, o que multiplica os pontos de vista sobre a história, além de operar a desconstrução das implicações de um dos mais resistentes pilares da estrutura narrativa e da construção ficcional literária: o narrador.

Dessa forma, as questões ligadas ao pensar a composição se integram ao conto desde os primeiros momentos, permanecendo e adquirindo status de tema. Paralelamente (ou internamente) à história de um fotógrafo diante da significação de uma cena observada e de seu posterior registro fotográfico, existe a história de sua própria construção (e também significação). Os meandros, os problemas, os questionamentos e os conflitos inerentes a esse processo se mostram fundamentais ao texto. Desse modo, como atesta Arrigucci Jr. (1995, p.229), As babas do diabo se mostra como "(...) uma narrativa que se realiza organicamente: consegue vincular, com perfeita coerência interna, as reflexões explícitas, sobre a técnica e as razões da narração, às necessidades do desenvolvimento temático". Os passeios hamletianos podem ser compreendidos, portanto, para além de meras paralisações no fluxo da narrativa, mas como parte relevante, se não a própria história.

As perambulações metaficcionais - realizadas por intermédio das estratégias apontadas anteriormente, a saber, a manifestação do fantástico (que põe em xeque a questão da noção e dos modos de representação da realidade na literatura), a analogia estabelecida entre fotografia e composição literária e ainda entre o ato de fotografar e o processo de significação textual e a oscilação de foco narrativo como reconhecimento das insuficiências pertinentes às diversas instâncias narrativas - traduzem, inevitavelmente, o posicionamento cortazariano em relação à produção literária.

Avesso a soluções simplificadoras e envolvido com a atividade crítica, Cortázar expõe no conto em questão a ideia de que é necessário se aproximar da autodestruição, provocar uma rebelião contra os convencionalismos literários propagados pela tradição, despir-se das estratégias de composição realista e tornar visíveis os problemas da criação para que surja o impulso renovador. Assim como Narciso, que - após se afogar atraído pelo próprio reflexo nas águas movido pela vaidade - ressurge transformado em flor de Lótus (que simboliza a beleza e o renascimento), a narrativa - na concepção do autor argentino - precisa se fazer reconhecer (ou expor seu próprio reflexo), chegar à (beira da) morte para ressurgir, em uma tentativa de renovação, transfiguração.

Esse renascimento, segundo Arrigucci (1995, p. 228) se efetiva através do "desnudamento irônico dos próprios procedimentos de construção do enredo", que impõe à narrativa um "movimento escorpiônico" que através da metalinguagem (e, por extensão, da metaficção) "desvenda os bastidores da ficção", apresentando "narrativas minadas pela radicalização da linguagem, que ameaça destruir ao mesmo tempo que 
constrói” em uma atitude que se observa em parte considerável da produção de Cortázar e que se torna decisiva à sua significação.

Em As babas do diabo, essa atitude "terrorista" volta suas armas às estruturas narrativas, aos paradigmas que compõem a poética do conto e aos frágeis sustentáculos da realidade, produzindo um "ataque" não violento, que visa o apuro estético e revela paixão pela arte da palavra e pelo trabalho com a linguagem escrita.

A expressão "babas do diabo" - que dá título ao conto de Julio Cortázar - faz referência a um fenômeno observável no outono europeu, quando jovens aranhas constroem finas teias pelas quais se locomovem pelo ar, com o auxílio do vento: "Tratase, pois, de uma metáfora popular já lexicalizada: os 'fios da Virgem' pertencem, na realidade, a jovens aranhas, que flanam, dependuradas, ao vento no céu límpido do outono europeu (...)" (ARRIGUCCI, 1995, p. 249). No texto, a expressão "fios da Virgem" é também usada para designar a mesma ocorrência: "os fios da Virgem também são chamados de babas do diabo" (CORTÁZAR, 2010, p.79).

Com base nessas informações, é possível inferir que o título - por extensão refere-se à própria narrativa em As babas do diabo, que está constantemente "por um fio", em meio a uma situação de instabilidade que o narrador - como ele mesmo afirma reiteradamente ao longo da história - é incapaz de resolver, à beira da paralisia e/ou do impasse. Essa reflexão nos diz que Cortázar, de forma sutil, já nos envolve em um novelo narrativo metaficcional, uma tessitura narrativa problemática, de frágil equilíbrio, que, por outro lado, não impede o leitor de alçar seus próprios voos no processo de leitura e significação.

No texto metaficcional, os papeis de crítico e autor são frequentemente representados pela mesma figura, aspecto que favorece ainda mais a integração e a associação de discurso literário e discurso crítico. A autoconsciência, portanto, é o aspecto que emerge com maior vigor desse cenário:

O limite entre ficção e crítica é ponto de convergência em que ficção e crítica assimilam as percepções um do outro, produzindo uma energia autoconsciente em ambos os lados. [...] Para a ficção isso significa a assimilação de uma perspectiva crítica na narrativa ficcional, uma autoconsciência da artificialidade de suas construções e uma fixação pela relação entre mundo e linguagem (CURRIE, 1995, p.2).

Em As babas do diabo, o teor crítico do discurso se manifesta explicitamente, provocando uma atmosfera de estranhamento diante da aparente suspensão do fluxo narrativo. Na verdade, crítica e ficção estão - como aponta Currie - em coexistência: o narrador, antes mesmo de se afirmar personagem da história, inicia seu trabalho através de um posicionamento crítico sobre a criação literária, ao mesmo tempo em que conta a história sobre a composição da história. A imbricação desses discursos (o discurso ficcional e o discurso crítico), isto é, a exposição da natureza autoconsciente do texto se faz presente desde o primeiro parágrafo do conto:

Nunca se saberá como isto deve ser contado, se na primeira ou na segunda pessoa, usando a terceira do plural ou inventando constantemente formas que não servirão para nada. Se fosse possível dizer: eu viram subir a lua, ou: em mim nos dói o fundo dos olhos, e principalmente assim: tu mulher loura eram as nuvens que continuam correndo diante de meus teus vossos seus rostos. Que diabo (CORTÁZAR, 2010, p.69). 
O trecho - ostensivamente metalinguístico - além de apresentar a consciência de que a linguagem dificilmente representa a experiência individual de forma completa e suficiente, por ser regida por convenções que visam organizar, mas que por vezes limitam as possibilidades expressivas - frustra as expectativas normalmente associadas à narrativa literária e ao próprio gênero conto.

Segundo as reflexões teóricas que compõem a teoria do conto - entre elas, algumas colocações realizadas pelo próprio Cortázar em textos como Alguns aspectos do conto - o gênero em questão tem uma economia própria; prescinde de acessórios, de excessos, limita-se à concisão e à concentração da totalidade de seus elementos em nome da significação:

O contista sabe que não pode proceder acumulativamente, que não tem o tempo por aliado; seu único recurso é trabalhar em profundidade, verticalmente, seja para cima ou para baixo do espaço literário. E isto que assim expresso parece uma metáfora, exprime, contudo, o essencial do método. O tempo e o espaço do conto têm de estar como que condensados, submetidos a uma alta pressão espiritual e formal para provocar essa 'abertura' a que me referia antes (CORTÁZAR, 2006, p.152)

O "rodeio" que dá início ao conto apresenta uma dupla ruptura: tanto com as expectativas do leitor em relação à narrativa, como com as convenções que identificam a narrativa literária breve. Entretanto, esse pode ser considerado um rodeio apenas aparentemente se a ideia de que a reflexão sobre a criação literária também é parte da história (senão a própria história) for aceita.

Ainda ocupado com as ponderações acerca das dificuldades da composição narrativa, o narrador - cuja identidade ainda é desconhecida pelo leitor, justamente devido à postergação do início da história "propriamente dita" - afirma o caráter extraordinário da experiência que busca traduzir pela linguagem literária, aspecto ao qual atribui sua hesitação em relação à maneira pela qual contará:

Durante a narração, se fosse possível ir beber um chope por aí e a máquina continuasse sozinha (porque escrevo à máquina), seria a perfeição. E não é uma maneira de dizer. A perfeição, sim, porque o insondável que aqui é preciso contar é também uma máquina (de outra espécie, uma Contax 1.1.2) e de repente pode ser que uma máquina saiba mais de outra que eu, tu, ela - a mulher loura - e as nuvens (CORTÁZAR, 2010, p.69).

A palavra "máquina" nesse trecho suscita ideias como objetividade, imparcialidade e precisão; elementos dos quais o narrador julga precisar para assumir definitivamente a tarefa de contar a história, tanto que afirma que a perfeição só seria atingida se fosse possível uma espécie de transferência do que foi capturado pela Contax para a máquina de escrever.

Consciente de que essa perfeição não existe, de que a máquina não prescinde da mão e da mente humanas e que é necessário um árduo trabalho de construção e criação, o narrador suscita o debate acerca da concepção do texto, buscando discutir a ideia de escrita literária como atividade motivada unicamente pela inspiração:

(...) se eu for embora, essa Remington ficará petrificada sobre a mesa com esse ar de duplamente quietas que as coisas móveis têm quando 
não se movem. Então tenho que escrever. Algum de nós tem que escrever, se é que isto vai ser contado." (CORTÁZAR, 2010, p. 69).

Mesmo diante do momento de aparente tomada de decisão - perceptível na expressão "tenho que escrever" - percebe-se que a indefinição suplanta os rompantes de certeza, instaurando a ambiguidade. Ao evocar a presença de um outro através da sentença "algum de nós tem que escrever", o narrador possivelmente se refere à máquina de escrever, entretanto, recorre - embora sutilmente - a uma instância narrativa alternativa que assuma com ele a responsabilidade de trabalhar verbalmente o "insondável". E é essa alternância que de fato se manifesta ao longo do texto.

A imersão nesse processo imaginativo provocaria a abertura a uma nova visão de mundo, mais consciente dos mecanismos que compõem e perpetuam certas convenções literárias que condicionam o olhar do leitor à passividade e à condição de simples receptor. Na narrativa cortazariana em análise, essa dinâmica de ruptura de paradigmas narrativos e de frustração de expectativas leva à reconsideração da própria noção de história como sucessão de acontecimentos de visibilidade e/ou impacto diegético, o que orienta o leitor a buscar enxergar para além do que é contado, sobretudo quando se leva em consideração a condição do narrador em relação ao material a ser narrado.

\section{Concluindo o passeio}

Assim como Roberto Michel amplifica suas dúvidas ao produzir ampliações da fotografia, Cortázar amplifica o sentido do texto em direção à questão da autorreflexividade e da discussão acerca da recriação da realidade pelo discurso literário expondo suas convenções, seus artifícios e suas fraturas. Essa estratégia pode ser considerada como fator de risco, já que por vezes impõe à narrativa pausas indagadoras que comprometem o andamento da história, ameaçando-a de paralisia.

O leitor é, portanto, convidado a flanêrie da ficção, orientado pelas (caóticas) colocações do duplo narrador e pelas evocações reflexivas da fotografia que - a despeito da impressão de paralisação narrativa - sugere um outro ângulo de compreensão do texto, amplifica as possibilidades de significação graças à liberdade e à responsabilidade que são oferecidas ao agora coautor do texto.

Os paseítos hamletianos dentro de la estructura misma de lo narado impõem um embate entre fluidez e autoconsciência narrativa. Ao se questionar sobre "ser ou não ser", ao inserir uma história dentro de outra, expondo as engrenagens mais confiáveis da estrutura narrativa no intuito de desmascará-las - assim como Hamlet encena uma peça autorreferencial com o objetivo de atingir a consciência do assassino de seu pai - a narrativa cortazariana denuncia uma literatura à beira da exaustão no mesmo sentido, porém, do pensamento de John Barth em The literature of exhaustion, texto no qual o termo "exaustão" remete menos a desgaste do que a necessidade de renovação. A narrativa está por um fio, mas é esse fio que também a sustenta no voo rumo ao recomeço e à sobrevivência.

\section{Referências}


ARRIGUCCI JUNIOR, D. O escorpião encalacrado: a poética da destruição em Julio Cortázar. São Paulo: Companhia das Letras

CORTÁZAR, J. As armas secretas. Trad.: Eric Nepomuceno. Rio de Janeiro: Civilização brasileira, 2010.

COUTINHO, E. F.. Julio Cortázar e a busca incessante da linguagem. In: COUTINHO, Eduardo F. (Org.). A unidade diversa: Ensaios sobre a nova literatura hispanoamericana. Rio de Janeiro: Anima, 1985. p. 17-46.

CURRIE, M. Metafiction. London and New York: Longman, 1995.

HUTCHEON, L. Narcissistic Nnarrative: The metaficional paradox. London And New York: Routledge, 1991.

WAUGH, P. Metafiction: The theory and practice of self-conscious fiction. London New York: Routledge, 2003.

Recebido em 13 de maio de 2018

Aceito em 23 de julho de 2018 